\title{
Erosion and the Hippos
}

\section{Paul Leyhausen}

In recent years several African national parks have been faced with the 'hippo problem' - a large population of hippos accused of causing serious erosion and habitat destruction. Should they be culled? Uganda decided yes, in the Rwenzori National Park (formerly Queen Elizabeth); but the Zaïre (formerly Belgian Congo) parks have always been regarded as strict nature reserves and no killing has been allowed. However, at a joint meeting of the Survival Service and the National Parks Commissions, at Kinshasa, last September, the question was raised in regard to the Virunga (formerly Albert) National Park. The commissions were asked to advise the Parks Administration on the possible relationship between the hippopotamus population and the erosion of land adjacent to the Semliki, Rutshuru and Rwindi rivers. It had been suggested that a hippopotamus population explosion in recent years was responsible for overgrazing and damage to the river banks, increasing erosion to such a degree that the whole river valley was threatened with denudation and destruction. Should the hippopotamus population be culled? Dr Paul Leyhausen was among the delegates who were able to visit the Virunga park in the course of the IUCN meetings, and in this note records his observations and conclusions on the problem and incidentally gives some idea of the complications of the situation.

When we visited the Virunga National Park, I paid particular attention to the erosion situation and, although the time was far too short for a detailed study, the following facts are obvious and the conclusions seem to me quite safe.

The volcanic soil of the Lake Idi Amin (formerly Edward) plains consists of ashes and decayed lava; the layers are many metres deep. Such soil is extremely fine-grained and does not cake hard when dry. It is therefore very susceptible to wind erosion, the wind blowing the dust away from the grass roots, thus exposing and desiccating them. Many of the erosion patterns in Virunga, especially the circular pattern encountered so frequently, are of this nature and quite independent of any hippopotamus activity.

When it is exposed to strong rains and rushing water, this soil is easily washed out. Any concentrated stream of water will soon rip out deep gullies, down which the water runs, undercutting the vegetation on either side. The erosion near the rivers and on the river banks is largely of this kind. Hippos moving in and out of the water for the most part use such 'natural' gullies. The wear and tear of their feet will certainly increase the downward movement of material in the gullies, especially the steeper ones, but the effect is insignificant compared with what a single heavy, tropical downpour can do.

Early records of the area seem to confirm that both heavy erosion and a very high hippopotamus population were features of the Lake Idi Amin plains and probably have been for thousands of years. A sizeable proportion of the mud which used to fertilise the lower Nile valley of Egypt every year before the advent of the Aswan Dam quite certainly came from there. The soil's fine grain keeps it well in suspension, and it will not be held back to any 


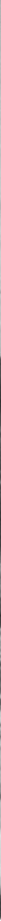

Norman Myers

great degree by the Sudd. In spite of all this, the plains have shown little change in recorded time.

The recent observed increase in the hippopotamus population may in fact be nothing but a restoration of former numbers; hippos had been considerably reduced by shooting before much of the area was included in the national park and at a time when the park personnel were unable to prevent poaching. However that may be, there is every evidence that, as conditions are now, even shooting off all the hippos would not stop or even appreciably slow down erosion.

Considering that we saw the plains at the end of the dry season*, the vegetation cover was still in fair shape, indeed lush over wide tracts, and there was no sign of serious overgrazing. Even in the most heavily grazed places the minimum height of the grass was 5 to $10 \mathrm{~cm}$. The heavy rains will soon mend this.

In conclusion, I would say that there is no evidence now of serious hippopotamus-caused erosion or of permanent damage from overgrazing. The advice should therefore be to leave well alone and keep the situation under observation. At a guess I should say that the present hippo population could well treble before it gave cause for worry. One suspects that in a number of other cases, when erosion has been diagnosed as being caused predominantly or even exclusively by biotic influences, the prime importance of geological and physical factors may have been overlooked or incompletely understood. An expert on soil geology and physical erosion should always be consulted before any management or culling schemes are drawn up, much less implemented.

* This dry season was reported to have been unusually wet. Editor 